A BOOLEAN ALGEBRA

Abstract and Concrete 


\section{INTRODUCTORY MONOGRAPHS IN MATHEMATICS}

General Editor

A. J. MOAKES, M.A.

Numerical Mathematics

A. J. Moakes

Exercises in computing with a desk calculating machine

Mathematics for Circuits

W. Chellingsworth

The Core of Mathematics

A. J. Moakes

An introduction to 'modern' mathematics

A Boolean Algebra

A. P. Bowran

Abstract and Concrete 


\title{
A BOOLEAN ALGEBRA
}

\author{
Abstract and Concrete
}

\author{
BY \\ A. P. BOWRAN, B.A. \\ LOUGHBOROUGH TRAINING COLLEGE
}

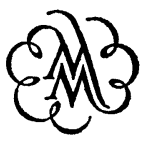

Macmillan Education 
Copyright (c) A. P. Bowran 1965

ISBN 978-0-333-03116-2 ISBN 978-1-349-00216-o (eBook)

DOI 10.1007/978-I-349-00216-0

MACMILLAN AND COMPANY LIMITED

St Martin's Street London WC2

also Bombay Calcutta Madras Melbourne

THE MACMILLAN COMPANY OF CANADA LIMITED

70 Bond Street Toronto 2

ST MARTIN'S PRESS INC

I75 Fifth Avenue Nerv York rooro NY 


\section{PREFACE}

This book is written for readers who have some experience of mathematics-up to about University entrance level. To help the less experienced student, the answers to many of the early exercises have been written out in full, and can thus be used as examples. Further exercises are provided in the Supplement.

Experience of teaching Boolean Algebra and its various applications to students from 16 to 20 years old has clearly shown two points:

(i) their desire for a rigorous development of the algebra,

(ii) their need of a solid link with their earlier mathematical experiences.

Chapter 1 is intended to provide the latter, by stressing the way in which the postulates have been used in the algebra of numbers and how the basic methods have been applied. It can be omitted.

A complete grasp of all the algebra of Chapter 2 before going on to its applications is not necessary. Care has been taken in the later chapters to refer back to the paragraph containing any theorem or method used, and the necessary algebra can be done then, if preferred.

Readers who find difficulty in starting with a completely abstract algebra can read Chapter 3 , on sets, before tackling the algebra, and then, when reading Chapter 2, they can imagine the elements of the algebra are sets. They could alternatively read something about sets from an elementary textbook (e.g. Sets for Schools).

Notation in mathematics is often a difficulty, especially before one form of notation has been generally accepted. The ' $+\cdot \cdot$ ' notation stresses the analogies with the algebra of numbers, but the beginner usually finds $\mathrm{A} \cup \mathrm{A}=\mathrm{A}$ more digestible than $\mathrm{A}+\mathrm{A}=\mathrm{A}$ ! I have found that most students, starting with the ' $U \cap$ ' notation, and given the choice for later working, use the ' $+\cdot$ ' signs.

It must be stressed that this book is not intended to be a textbook on sets, logic, etc., but merely deals with some of their aspects which provide opportunities of applying the algebra. Chapter 7 suggests further reading on each of these subjects.

We thank Mr. D. P. St. Barnard and The Observer for their permission to use some of the 'Braintwisters'. 


\section{CONTENTS}

Preface

PAGE

Chapter 1. Introduction 1

2. A Boolean Algebra 7

3. Sets 17

4. Truth Tables 30

5. The Algebra of Circuits 38

6. Choice and Chance 46

7. Men and Books 50

8. Supplementary Notes and Exercises 52

Answers to some Exercises

$\begin{array}{ll}\text { Index } & 93\end{array}$ 